Muséologies

Les cahiers d'études supérieures

muséologies

\title{
L'homme : un artisan, dans sa vie professionnelle comme dans sa vie privée. Benoît Gauthier, Directeur du Musée québécois de culture populaire
}

\section{Louise Champoux-Paillé}

Volume 3, numéro 1, automne 2008

URI : https://id.erudit.org/iderudit/1033582ar

DOI : https://doi.org/10.7202/1033582ar

Aller au sommaire du numéro

Éditeur(s)

Association Québécoise de Promotion des Recherches Étudiantes en Muséologie (AQPREM)

ISSN

1718-5181 (imprimé) 1929-7815 (numérique)

Découvrir la revue

Citer ce document

Champoux-Paillé, L. (2008). L'homme : un artisan, dans sa vie professionnelle comme dans sa vie privée. Benoît Gauthier, Directeur du Musée québécois de culture populaire. Muséologies, 3(1), 100-107. https://doi.org/10.7202/1033582ar d'utilisation que vous pouvez consulter en ligne. 
Dialogue trois

L'homme : un artisan, dans sa vie

professionnelle comme dans sa vie privée

\section{Benoît Gauthier,}

Directeur du Musée québécois

de culture populaire

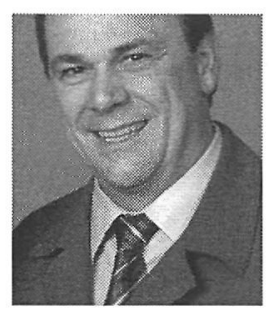

[ réalisé par Louise Champoux-Paillé le 23 mai 2008]

Titulaire d'une maîtrise en études québécoises avec majeure en histoire économique, Benoit Gauthier croyait faire carrière dans le domaine de la recherche et de l'enseignement en entreprenant un doctorat en histoire, scolarité qu'il compléta sans par ailleurs déposer sa thèse, sa soif de réalisations pratiques étant plus forte. Sa carrière débute par la réalisation de différents mandats de consultation dans la mise sur pied de lieux d'interprétation et, plus particulièrement dans le domaine du patrimoine industriel, milieu qu'il privilégie tout naturellement étant donné sa formation de base en histoire économique. Benoît Gauthier devient ainsi muséologue par la pratique en faisant équipe à ses débuts avec des professionnels du milieu, Paul-Louis Martin, Jean Provencher et Georges Léonidoff, qui lui transmettent dans un sens actif le savoir et le savoir-faire muséaux. Homme "de terrain " avant tout, il prend alors conscience qu'un travail d'implantation et de développement répond plus à ses intérêts qu'un travail de consultation. Menuisier dans ses temps libres, il aime créer, façonner, réaliser. L'opportunité de la direction du Musée de culture populaire se présente en 2005 et il décide d'y plonger avec la passion de l'artiste et de l'artisan. 
Le Musée québécois de culture populaire que dirige Benoît Gauthier a été créé en 2001. Il prenait le relais du Musée des arts et traditions populaires du Québec qui avait été mis en dormance en 1999. Ce changement d'appellation s'inscrivait dans le processus de relance de l'institution et marquait le changement de mission et d'orientation. Le nouveau musée a ouvert ses portes en 2003. Sa mission s'affirme ainsi :

- Reconnaître, préserver et mettre en valeur ce que les cultures populaires produisent, consomment et lèguent en patrimoine matériel (objets, environnements) et immatériel (savoirs, savoir-faire);

- Contribuer au développement et au rayonnement culturel de la ville de Trois-Rivières ;

- Participer au développement de l'industrie touristique de TroisRivières et de la Mauricie ;

- Rendre accessible le musée aux personnes démunies et soutenir les actions culturelles des groupes et des organismes communautaires de la ville de Trois-Rivières.
Louise Cham pouX-PAIllé Brossez-nous « la petite histoire* du musée. BENOîT GAUTHIER

Dès le début des années 1930, les Trifluviens ont multipliéles efforts afin que la ville se dote d'un musée en bonne et due forme. Bien qu'il y ait eu quelques projets présentés aux instances gouvernementales, ce n'est que vers la fin des années 1980 que les promoteurs, principalement l'abbé Gilles Boulet, l'Université du Québec à Trois-Rivières (UQTR) et la député provinciale du comté, Lise Bacon, réunissent les fonds nécessaires pour amorcer la construction du musée au début des années 1990. Le souhait du principal dirigeant de l'époque, l'abbé Gilles Boulet, était d'inscrire celui-ci dans le sillon des musées régionaux et locaux créés par Georges Henri Rivière, visant à conserver, à faire connaître et à apprécier les arts et traditions populaires d'une population. Le Musée de Trois-Rivières est alors nommé Musée des arts et traditions populaires du Québec et repose sur deux collections importantes, soit celle de l'ethnologue Robert Lionel Séguin, réunissant des objets témoignant de la civilisation traditionnelle québécoise, ainsi qu'une collection d'archéologie préhistorique amérindienne et européenne du professeur René Ribes de l'UQTR.

Ayant connu un grand succès au cours de la première année, le musée rencontre progressivement de graves difficultés qui entraînent sa mise en dormance en 1999. Plusieurs facteurs sont à l'origine de ces difficultés : un essoufflement de 
la fréquentation qui ne reposait que sur la population trifluvienne, un concept scénographique démodéfaisant appel à un seul sens - celui du regard -, présentant à répétition des objets de même nature expliqués par des cartels "interminables", le rendant extrêmement intellectuel, et une dette importante issue de la construction. Les visiteurs de l'époque comparaient le musée trifluvien à d'autres musées comme le Musée de la civilisation et nous ne pouvions rivaliser avec la nouvelle muséographie de l'instant qui tournait le dos à ce concept des années 1950.

Soucieux de conserver cette institution, les Trifluviens créent alors un comité de relance composé de gens de la région et de spécialistes $d u$ milieu, dont René Rivard du Bureau d'études Cultura et Robert Trudel de la Citéde l'énergie. Ce comité propose les grandes orientations, une nouvelle programmation basée surl'approche de thématiques et relancele musée sousl'appellation de Musée québécois de culture populaire.

Louise ChampouX-Paillé

Quels sont les facteurs de succès du Musée québécois de culture populaire?

BeNOÎT GAUTHIER

Une combinaison de plusieurs raisons expliquele succès de la relance. Je les résumerai ainsi :

- Une programmation axée sur la culture populaire, visant à mettre en valeur toutes les cultures populaires dans ce qu'elles ont de diversité et de pluralité, permettant ainsi un large spectre d'expositions potentielles.

- Une intégration dans la stratégie de développement de la région et une complicité avec les autres institutions culturelles de la région.

- Une mise en valeur nouvelle de la prison, marque distinctive de l'institution.

- Une stratégie et des actions soutenues pour faire de ce musée un attrait touristique culturel majeur à Trois-Rivières et en Mauricie.

- Une complicité avec le réseau scolaire.

Parlons de notre programmation : initialement, le comité de relance avait suggéré une programmation axée sur une succession de grandes thématiques suivant un cycle de deux ans. Ainsi, au cours des deux premières années de la relance, nous avons conçu une programmation exploitant le thème de l'alimentation pour ensuite aborder celui de l'évasion. Cette expérience nous a montré les difficultés d'une telle approche : impossibilité technique et financière de remplacer un thème dans un aussi bref delai, envergure de l'investissement marketing requis pour vendre la nouvelle thématique et la remplacer dans la tête des visiteurs, manque de continuité dans les expositions et les activités éducatives et culturelles et perception réductrice par le public, le musée étant alors appelé par celui-ci le "musée de l'alimentation". 


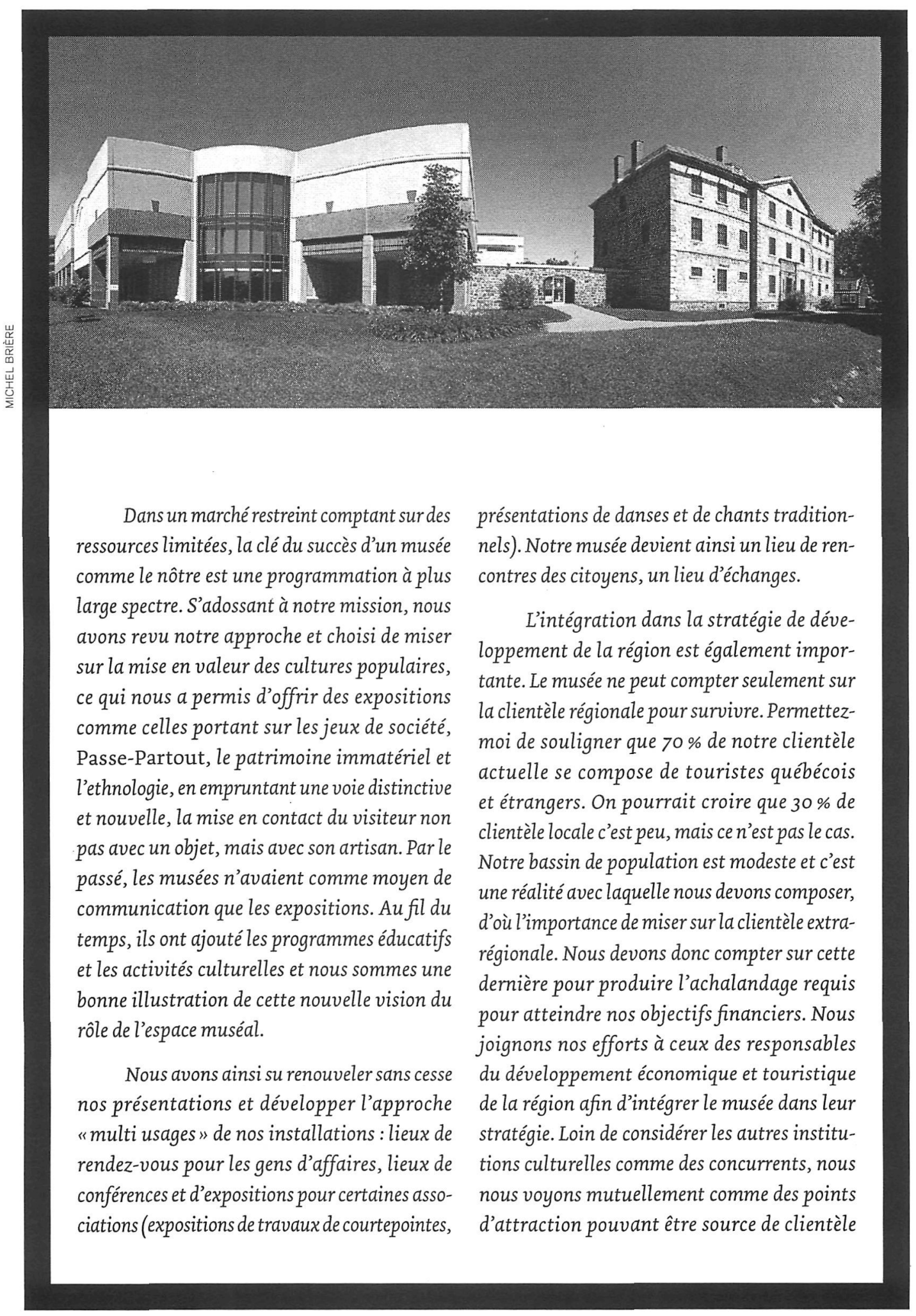


pour l'autre. Notre optique est la suivante à cet égard : plus il y a d'institutions culturelles qui offrent des produits et services attrayants, plus nous aurons de touristes et plus ces derniers demeureront dans la région. Nos études démontrent que l'expérience touristique de nos visiteurs est de plus en diversifiée : alors qu'il y a quelques années c'était l'offre d'activités de type "nature " qui interpellait principalement les visiteurs, aujourd'hui l'offre culturelle des institutions de la Mauricieles intéressent de plus en plus. Notre stratégie pourl'instant en est une d'interception auprès des touristes étrangers de passage dans la région, mais nous sommes conscients que, compte tenu que notre population n'est pas en croissance, la stratégie gagnante est de développer la clientèle extrarégionale, ce qui requerra davantage d'investissements promotionnels et publicitaires en collaboration avec nos partenaires.

Comme autre elément, nous avons misé surla prison sous sa forme d'origine. Dans les premières années d'existence du musée, la prison certes faisait partie du complexe muséal, mais elle avait été revue pour en faire un beau site à visiter. On avait alors vidéla prison de tout ce qui pouvait l'évoquer, eliminéles graffitis, peinturé les murs en blanc : brefon avait fait disparaître toute trace d'une vie carcérale.

Le comité de la relance a épousé une nouvelle orientation pour cette prison et décidéde la présenter telle qu'elle était au début des années 1970, en comptant sur des photographies prises par le ministère de la Culture de l'époque pour classer la prison comme monument historique. Il a ajouté, comme caractéristique unique, des visites guidées par d'anciens prisonniers, ce qui bonifiait sa valeur unique et permettait d'exploiter avec crédibilité un autre axe de communication, soit porter un regard sur les eléments marginaux de notre société.

Le succès de la relance a également reposé surles activités éducatives. Différents projets ont étémis de l'avant, ce qui nous a permis de rejoindre, en moins de quatre ans, plus de $50 \%$ de cette clientèle et de nous introduire ainsi dans le panier de référencement des activités intéressantes pour les familles de la région. Pour ce faire, nous avons investi dans une exposition permanente dédiée uniquement aux enfants, laquelle constitue le point d'ancrage de nos activités éducatives. C'est une exposition fort importante pour nous, que nous renouvellerons à l'automne 2009.

Enfin, notre dernier facteur de succès est l'appui de la population et des médias locaux. Le comité de relance avait, à cet égard, identifié comme crucial l'établissement de relations harmonieuses avec la population et les médias, la direction de départ du musée ayant entretenu des relations plutôt tendues avec les journalistes de l'époque. Dans cette optique, le conseil d'administration, qui a été composé lors de la 
relance et qui nous accompagne toujours, a constitué une clé de rapprochement avec la population, celui-ci étant constitué de représentants des principaux acteurs de la société trifluvienne et pouvant ainsi contribuer à un changement de notre image auprès de nos différents publics.

\section{Louise ChampouX-Paillé}

Récemment, la région mauricienne a été identifiée par le ministère de la Culture et des Communications comme l'une des deux régions expérimentales pour tester le concept de cellules régionales d'expertise en muséologie (CREM). Sûrement que l'approche de concertation développée par Médiat Muse au cours des dernières années constitue un bon terreau pour tester un tel concept?

\section{BENOÎT GAUTHIER}

Créé en 1987, l'organisme Médiat Muse est la première association régionale quebécoise du genre et regroupe aujourd'hui une trentaine d'institutions culturelles des régions de la Mauricie et du Centredu-Québec; il a pour but de fournir un forum d'échange et de concertation de nos efforts. Il a mis del'avant, au cours des années, différents projets rassembleurs tels que "Rodolphe Duguay en mémoire 1891-1991", peintre-dessinateur-graveurillustrateurdela région, "Le goût del'eau», le «Bois œuvre» et le «Feu». Cette approche de concertation nous aura permis d'atteindre une plus grande visibilité régionale et extrarégionale, d'organiser de vastes campagnes de communication et de favoriser des échanges et le partage d'expériences en regard de nos modes de fonctionnement et des défis que nous avons à relever en région.
Pourle Musée québécois de culture populaire, la concertation et la solidarité régionale ont été des eléments stimulateurs de développement. Il ne fait aucun doute dans notre esprit que cette initiative du gouvernement provincial nous permettra d'elaborer de nouveaux projets, d'accentuer l'entraide et la mise en commun des ressources.

Louise Cham poux-Paillé On dit souvent qu'une fois les cinq premières années franchies avec succès, l'institution peut penser à la pérennité. Quels sont vos projets pour le futur?

BENOÎT GAUTHIER

À court terme, pourl'année 2009, nous travaillons sur une exposition qui mise surl'un de nos avantages uniques, la prison. La thématique de cette prochaine exposition, "Les grands procès criminels du XIXe siècle", mettra en valeur les pièces à conviction et proposera une lecture de ces événements dans une perspective de transformation de la société québécoise.

Sur un horizon de moyen terme, nous allons continuer à privilégier les activités thématiques qui nous permettent de renouveler l'intérêt pour nos activités tout en développant le créneau du patrimoine immatériel, folklore et contes. À cet égard, nous collaborons présentement au projet d'inventaire des ressources ethnologiques du patrimoine immatériel del'Université Laval. Nous avons organisé dans le cadre de ce partenariat une exposition intitulée Passeurs de traditions, mais nous souhaitons aller plus loin 
et devenir un lieu de diffusion et de transmission du patrimoine où nous présenterons des spectacles de chants et de danses traditionnels. Conséquemment, nous développons des collaborations avec le Conseil québécois du patrimoine vivant et d'autres organismes voués à la diffusion de ce patrimoine. Concevant le musée comme un lieu de rassemblement et un foyer d'activités culturelles, nous souhaitons développer davantage de partenariats avec d'autres institutions culturelles de la région, comme l'Orchestre symphonique de Trois-Rivières, et avec des établissements d'enseignement, dont le collège Laflèche, pour mettre sur pied des activités éducatives en lien avec la création d'un centre de démonstration en sciences.

Comme jel'ai mentionné, je voisle musée comme un lieu d'animation culturelle où la population apprécie se rencontrer. Nous travaillons dans un contexte d'un édifice muséal, mais je conçois aussi bien que l'activité muséale puisse se retrouver dans un centre commercial, comme le Musée du Nouveau-Brunswick dans la ville de Saint John, lieu de rencontres et d'activités pour les familles, les personnes agées et la population dans son ensemble. Autre exemple de cette approche, l'Hôtel-Musée Wendake, concept hôtelier créé parl'architecte Pierre Thibault qui abrite un musée mettant en valeur la richesse de la culture et des savoir-faire des Hurons-Wendats. Cet architecte poursuit l'objectif de créer des espaces de vie enracinés dans la culture et je pense que les musées, du moins les musées thématiques comme le nôtre, doivent s'inspirer d'une telle philosophie. Trop souvent, nos musées ont été conçus pour des fins uniques d'exposition et de conservation, ce qui les rend peu flexibles pour s'adapter aux expositions thématiques ou aux différents usages qu'ils peuvent avoir. C'est une problématique avec laquelleje suis fréquemment aux prises au musée, la flexibilité des installations n'étant pas un élément recherché par les instigateurs du projet à l'époque. Je crois que des musées comme le nôtre devraient jouir d'une extrême flexibilité pour pouvoir s'adapter rapidement à de nouveaux visiteurs ou à de nouveaux utilisateurs, comme, sans vouloir offusquer vos lecteurs, un centre commercial avec ses espaces modulaires, facilement adaptables aux besoins de nouveaux usagers. Je suis de ceux qui favorisent une nouvelle approche de la relation musée-visiteur. Les musées que nous avons mis en place au Québec au cours des années 1970 et 1980 sont des musées qui reflètent la pensée de l'age industriel : on produit des expositions et on offre un produit à des clients. Pour moi, à l'âge du savoir, celui d'aujourd'hui, nous devrions davantage parler d'usagers et de multiples usages, de manière à pouvoir s'adapter constamment à leur imaginaire et à leur désir de ce que doit être un espace muséal.

Enfin, nous songeons également à nous doter à moyen terme d'une collection permanente axée sur la culture populaire québécoise 
afin de bien camper notre différence dans l'offre muséologique quebécoise. Nous avons déjà entrepris des recherches afin de bien définir ce que nous entendons parle terme "culture populaire", ce qui peut paraître à prime abord facile à définir, mais qui est, je vous l'avoue, plus complexe qu'on le croit. À titre d'exemple, nous avons présenté une exposition sur Les ventes de garage, nous en préparons une autre sur Le Grand Prix automobile de Trois-Rivières et nous envisageons une exposition sur Les bands de garage, c'està-dire le phénomène d'utilisation du garage ou du sous-sol des parents parles jeunes qui veulent créer un nouveau groupe musical. C'est dans ces lieux que la majorité des groupes musicaux québécois ont vu le jour depuis les années 1950. Forts de ces expériences sur ces différentes facettes de la culture populaire, nous pouvons maintenant envisager une exposition permanente sur la culture populaire des Québécois. Toutefois, la conception d'une telle exposition permanente est cruciale pour établir notre marque distinctive et assurer notre pérennité et elle est stratégique pour attirer la clientèle touristique internationale. L'industrie du voyage est une industrie à long terme et il est important de présenter une programmation attrayante sur un tel horizon.
Louise Cham poux-Paillé Quel est actuellement le plus grand enjeu des musées sur le plan des ressources humaines? BENOÎT GAUTHIER

Je dirais que c'est la relève. Les musées étant généralement de petite et moyenne taille et les postes de direction étant occupés par des gens de quarante ou cinquante ans, les jeunes n'ont pas l'espace organisationnel nécessaire pour faire face à de nouvelles responsabilités. Ils doivent souvent aller dans une autre institution s'ils veulent progresser professionnellement. Nous travaillons toujours à batir notre relève. C'est d'autant plus important que plusieurs dirigeants de musées prendront prochainement leur retraite. Il faut qu'on mette de l'avant des plans de relève au sein de chacune de nos institutions, qu'on mette en place des programmes de transfert de savoir et que nos institutions d'enseignement mettent l'épaule à la roue.

Je terminerai en disant que ce qui caractérise les musées, ce sont leurs ressources humaines, dédiées à la mission de leur organisme et animées d'un grand esprit de service à la communauté. Je peux en témoigner avec l'équipe qui m'entoure. Il faut s'assurer de conserver ces talents dans nos institutions et voir en tant que gestionnaire à être de généreux passeurs de savoir-être et de savoir-faire muséal. 